\title{
RIETVELD REFINEMENT IN SUPER DUPLEX STAINLESS
} STEEL

\author{
Lima, A. N. C. ${ }^{*}$; Muniz, F. T. L. ${ }^{2}$; Batista, A. M. L. ; Sasaki, J. M. ${ }^{2}$ \\ ${ }^{1}$ Department of Metallurgical and Materials Engineering, Universidade Federal do Ceará, Fortaleza, Ceará, Brazil \\ ${ }^{2}$ Department of Physics, Universidade Federal do Ceará, Fortaleza, Ceará, Brazil \\ *nelcionecarvalho@gmail.com
}

\begin{abstract}
A X-ray powder diffraction patterns can provide many structural information, for instance, distance between atomic planes, preferential orientation and microstrain/crystallite size. Computer programs based on the Rietveld refinement method are commonly used to extract structural parameters as well as the instrumental parameters. However, many of these programs are not applied in rolled steels that present high level of microstrain and texture. This work presents a computer program capable of performing Rietveld refinement in laminated super duplex steel samples using adapted model for a number of preferred orientations[1]. The simulation of $\mathrm{x}$-ray powder diffraction patterns of martensite and austenite phases for two analytical distributions function for microstrain, will be shown. The instrumental parameters such as, flat surface, axial divergence, specimen transparency and receiving slit functions[2] were determined using two standard reference samples $\left(\mathrm{LaB}_{6}\right.$ and $\left.\mathrm{CeO}_{2}\right)$.
\end{abstract}

[1] DOLLASE, W. A. Correction of intensities for preferred orientation in powder diffractometry: Application of the March model. J. Appl. Cryst., v. 19, p. 267-272, 1986.

[2] KLUG, H. P.; ALEXANDER, L. E. X-ray Diffraction Procedures For Polycrystalline and Amorphous Materials. 2 ed. Canada: Wiley Interscience, 1974. 